\title{
DETEKSI DINI KANKER SERVIKS DENGAN PEMERIKSAAN IVA DI WILAYAH KERJA PUSKESMAS MONGCONGLOE KAB.MAROS
}

\author{
https://doi.org/10.33024/jkpm.v4i6.4385 \\ Jamila Kasim $^{1 *}$, Firawati ${ }^{2}$, Arisna Kadir ${ }^{3}$ \\ ${ }^{1-3}$ STIKES Nani Hasanuddin Makassar \\ Disubmit: 25 Mei 2021 Diterima: 05 Juni 2021 Diterbitkan: 01 Desember 2021 \\ Email Korespondensi : jamila@stikesnh.ac.id
}

\begin{abstract}
ABSTRAK
Latar belakang Kanker serviks terus menjadi kanker umum pada wanita di seluruh dunia, terutama di daerah yang kurang berkembang di mana gejala stadium lanjut sering terjadi. Kanker serviks penyebab utama kematian akibat kanker pada wanita di negara berkembang. Deteksi dini kanker serviks dapat dilakukan dengan dengan inspeksi visual asam asetat (IVA) memberikan cara yang paling efektif untuk skrining kanker serviks. Implikasi untuk Praktik Keperawatan Perawat berada dalam posisi kunci untuk memberikan pendidikan kesehatan, Tujuan kegiatan ini agar masyarakat khususnya wanita dapat mengetahui tentang kanker serviks dan deteksi dini dengan pemeriksaan metode IVA test. Metode ceramah dilakukan kepada masyarakat khususnya wanita di wilayah kerja puskesmas moncongloe kab.maros. Hasil ibu ibu bisa menjelaskan tentang kanker servik dan deteksi dini pemeriksaan IVA Pelaksaanan kegiatan penyuluhan kesehatan bekerja sama dengan Puskesmas Moncongloe dan dibantu oleh mahasiswa Keperawatan dan kebidanan STIKES Nani Hasanuddin Makassar yang dilaksanakan pada bulan Maret 2021. kesimpulan bertambahnya pengetahuan wanita di wilayah kerja puskesmas mongcongloe khususnya dusun panikang tentang kanker serviks dan deteksi dini dengan pemeriksaan metode IVA test. Saran Diharapkan wanita dapat memeriksakan kesehatannya dengan pemeriksaan IVA tes secara mandiri di Puskesmas Mongcongloe serta untuk meningkatkanan perilaku ibu diharapkan peran serta dari tenaga kesehatan, kader dan khususnya keluarga.
\end{abstract}

Kata kunci : deteksi dini , IVA, Kanker Serviks .

\begin{abstract}
Background Cervical cancer continues to be a common cancer in women worldwide, especially in less developed areas where advanced symptoms are common. Cervical cancer is the leading cause of cancer death in women in developing countries. Early detection of cervical cancer by visual inspection of acetic acid (IVA) provides the most effective way to screen for cervical cancer. Implications for Nursing Practice Nurses are in a key position to provide health education. The purpose of this activity is so that the public, especially women, can find out about cervical cancer and early detection by means of the IVA test method. The lecture method was carried out to the community, especially women in the working area of the Moncongloe Community Health Center, Maros Regency. The results of mothers can explain cervical cancer and early detection of IVA
\end{abstract}


examinations. Implementation of health education activities in collaboration with the Moncongloe Community Health Center and assisted by Nursing and midwifery students STIKES Nani Hasanuddin Makassar which was held in March 2021. Conclusion is increasing knowledge of women in the working area of the Mongcongloe Community Health Center in particular. dusun panicang about cervical cancer and early detection by examining the IVA test method. Suggestion It is hoped that women can have their health checked by independent IVA tests at the Mongcongloe Community Health Center and to improve maternal behavior, the participation of health workers, cadres and especially families is expected.

Key words: early detection, IVA, cervical cancer.

\section{PENDAHULUAN}

Menurut perkiraan International Agency for Research on Cancer (IARC) beban kanker di Eropa, sekitar 33.000 wanita didiagnosis menderita kanker serviks dan 15.000 meninggal akibat penyakit tersebut pada tahun 2018.1 Perkiraan ini menyangkut kawasan Eropa sebagaimana ditetapkan oleh Perserikatan Bangsa-Bangsa . Tingkat kejadian sangat bervariasi di Eropa, dengan tingkat kejadian standar usia (ASIR) mulai dari kurang dari 5/100000 di Malta $(3,5)$, Swiss $(3,8)$ dan Finlandia $(4,7)$ (Arbyn et al., 2021)

Di Indonesia penyakit ini merupakan penyakit kedua setelah kanker payudara. Jumlahnya 23,4 per 100.000 orang. Angka kematian adalah 13,9 per 100.000 orang. Ini menunjukkan bahwa setiap tahun 50 wanita meninggal karena kanker serviks(Yuliani, Lusia, \& Widiati, 2020).

Metode IVA adalah metode deteksi dini yang sudah dicanangkan oleh pemerintah secara gratis bagi WUS (Chrystianty, Muarrofah, \& Puspitasari, 2021) Pemeriksaan IVA adalah sebuah pemeriksaan skrinning pada kanker serviks dengan menggunakan asam asetat 3-5\% pada inspekulo dan dapat dilihat dengan pengamatan secara langsung, cara ini dilakukan untuk melihat perubahan warna yang terjadi pasca dilakukan olesan, perubahan warna ini dapat langsung di amati setelah 1-2 menit pasca pengolesan dengan mata telanjang(Fariningsih \& Pasaribu, 2020)

Skrining adalah salah satu cara untuk menemukan lesi pre kanker dan kanker pada stadium dini(Eka Vicky Yulivantina et al., 2020)Tingginya angka penderita kanker serviks di Indonesia disebabkan oleh hanya 5\% yang melakukan skrining kanker serviks, karena kanker serviks tidak menimbulkan gejala dan sehingga kesadaran wanita kurang untuk memeriksakan kesehatannya. Setiap wanita usia subur harus termotivasi untuk melakukan Tes IVA(Vani Olin Arysha .,dkk 2020)

Pencegahan dan Deteksi Dini Kanker pada wanita Indonesia meliputi kegiatan promosi, pencegahan , deteksi dini, dan tindak lanjut. kesadaran masyarakat diharapkan dapat meningkat dalam pencegahan risiko kanker dan deteksi dini kanker untuk mengurangi penyakit, komplikasi akibat kanker (Kemenkes, 2015 dalam Dyah Restuning Prihati,dkk.,2021))

Pencegahan kanker serviks sangatlah penting,karena pemahaman akan muncul kesadaran tentang pentingnya menjaga kualitas hidup dan menghindari bahaya kanker serviks tes IVA adalah bagian dari kesadaran wanita akan kesehatan reproduksi. Sikap ibu merupakan peran penting dalam pembentukan perilaku dalam pemeriksaan IVA. (Monica \& Ulfa, 2020)

Deteksi dini dengan metode IVA mudah dilakukan, biaya pemeriksaannya murah, hasilnya cepat diketahui, memiliki tingkat spesifisitas dan sensitifitas 
yang akurat, dapat dilakukan oleh dokter, bidan yang sudah mendapat pelatihan. Tes IVA dilakukan dengan cara mengoleskan asam asetat 3-5\% pada lidi kapas dan dioleskan ke leher rahim / serviks (Permenkes, 2015). Setelah leher rahim digosok dengan asam asetat, kemudian diamati dan diamati sebentar, setelah itu dilakukan evaluasi. Hasil pemeriksaan IVA, dikelompokkan normal yaitu bila hasil pemeriksaan IVA negatif, inflamasi / serviks / atipikal yaitu gambaran serviks tidak khas akibat infeksi baik akut maupun kronik pada serviks, IVA positif adalah adanya bercak putih / lesi prakanker, yang dicurigai sebagai kanker serviks. Pemeriksaan IVA merupakan program skrining untuk menemukan kanker serviks. Karena saat ini kanker serviks banyak ditemukan pada stadium lanjut (Nurbaity, Zulfendri, \& Rochadi, 2020)

Hasil Pengabdian masyarakat yang dilakukan (Tini Wartini,.dkk, 2020) di simpulkan dengan pemberian penyuluhan dapat meningkatkan pengetahuan tentang kanker serviks.

Hasil analisis penelitian (Nurbaity et al., 2020) menunjukkan bahwa tidak ada hubungan antara variabel pendidikan dan pendapatan dengan keputusan untuk melakukan Tes IVA. Sedangkan variabel yang memiliki hubungan dengan keputusan untuk melakukan Tes IVA adalah variabel pengetahuan

Puskesmas mongcongloe sebelumnya pernah menyelenggarakan penyuluhan tentang pentingnya pemeriksaan IVA, namun rata-rata dari ibuibu yang hadir dalam acara penyuluhan kami masih belum mengetahui tanda dan gejala awal dari kanker serviks, namun ada beberapa ibu-ibu yang sudah mengetahui mengetahui tanda dan gejala awal kanker serviks, sehingga disimpulkan masih Kurangnya pengetahuan dan kesadaran wanita di wilayah kerja puskesmas mongcongloe,sehingga kami dari tim pengabdian ingin bertujuan ingin melakukan penyuluhan dimana merupakan salah satu upaya untuk meningkatkan pengetahuan wanita mengenai pentingnya pemeriksaan kesehatan alat reproduksi sendiri. Pengetahuan yang lebih dapat meningkatkan kesadaran tentang pentingnya memeriksa kesehatan alat reproduksi khususnya tindakan preventif deteksi dini kanker serviks dengan pemeriksaan IVA Test, dilakukan dalam pencegahan kanker serviks bagi wanita usia produktif di wilayah kerja puskesmas mongcongloe.

\section{MASALAH}

Alasan kami memilih wilayah kerja Puskesmas mongcongloe kab.maros sebagai tempat pengabdian ini adalah di Aula TK Zam-zam dusun Panaikang. terdapat ibu-ibu yang menghadiri Acara Penyuluhan kami tentang pentingnya mendeteksi dini kanker serviks dengan pemeriksaan IVA. Berdasarkan hasil pengamatan kami, masih banyak masyarakat diluar sana khususnya para ibu yang tidak mengetahui tentang pentingnya mendeteksi dini kanker serviks meengenal tanda dan gejala awal dari kanker serviks.

Puskesmas mongcongloe sebelumnya pernah menyelenggarakan penyuluhan tentang pentingnya pemeriksaan IVA, namun rata-rata dari ibuibu yang hadirdalam acara penyuluhan kami masih belum mengetahui mengetahui tanda dan gejala awal dari kanker serviks, namun ada beberapa ibu-ibu yang sudah mengetahui mengetahui tanda dan gejala awal kanker serviks. Setelah kegiatan pengabdian ini agar para ibu-ibu dapat mengetahui dan mendeteksi secara dini dari kanker serviks dan juga dapat meningkatkan motivasi sesama wanita. 


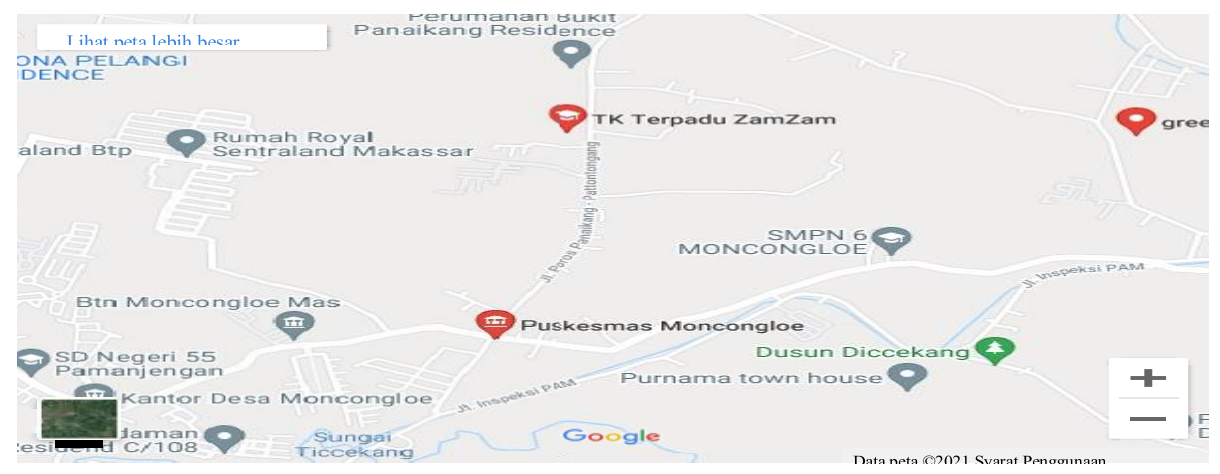

2.1 Peta Lokasi Kegiatan

\section{METODE}

1. Tujuan Persiapan

Tahap persiapan dari kegiatan adalah persiapan materi, dan leaflet sebagai alat promosi kesehatan. Pembuatan materi dan penyajian leaflet dilakukan tanggal 10 Maret 2021 pemilihan tempat berkordinasi dengan pihak puskesmas, pada tanggal 16 maret 2021 dilakukan Penyuluhan kanker serviks tentang pemeriksaan IVA. pada hari Pelaksanaan di hadiri oleh Ibu - Ibu , di wilayah kerja Puskesmas moncongloe.Teknis pelaksanaan dilaksanakan 1 hari bekerja sama dengan pihak puskesmas. Pelaksanaan dimulai pada pukul 09.00 di Aula TK Zam-zam . Penyuluhan di isi oleh yaitu Dosen STIKES Nani Hasanuddin yang di bantu oleh mahasiswa Jurusan Keperawatan dan kebidanan dihadiri oleh 25 peserta dari wilayah puskesmas Mongcongloe. Penyuluhan yang diberikan terlebih dahulu apa itu kanker serviks, tanda dan gejala serta bagaimana cara pencegahan dengan pemeriksaan IVA . penyuluhan kesehatan dilakukan dengan diskusi secara langsung dengan tetap menjaga protokol kesehatan pada masa pandemi covid-19. Peserta aktif saat kegiatan dan antusias mendengarkan orientasi tersebut. Hasil akhir dari pengabdian ini memberikan kesadaran pada masyarakat khususnya perempuan untuk dapat menjaga kesehatan serta mencegah terjadinya kanker serviks dengan melakukan pemeriksaan IVA.

a. Struktur

Peserta hadir sebanyak 25 orang. Waktu pelaksaan dan tempat sudah dilaksanakan sesuai dengan perencanaan serta perlengkapan yang dilakukan untuk penyuluhan sudah tersedia dan sudah digunakan sebagaimana mestinya. Penyampaian pada saat orientasi kesehatan menarik karena bahasa yang digunakan komunikatif, peserta dapat mengerti materi yang diberikan serta proaktif juga ditunjukan oleh peserta.

b. Proses

Pelaksnaan kegiatan pukul $09.00 \mathrm{~s} / \mathrm{d}$ selesai. Sesuai dengan jadwal yang telah ditentukan.

c. Hasil

Hasil akhir dari pengabdian ini memberikan kesadaran pada masyarakat khususnya wanita untuk dapat menjaga kesehatan serta mencegah terjadinya kanker serviks dengan melakukan pemeriksaan IVA. 


\section{HASIL DAN PEMBAHASAN}

Metode pelaksanaan kegiatan ini dilaksanakan 1 hari di Aula TK Zam zam dusun panaikang moncongloe. penyuluhan dilakukan dengan diskusi secara langsung dengan tetap menjaga protokol kesehatan. kegiatan penyuluhan tentang pemeriksaan IVA di wilayah kerja Puskemas moncongloe terlaksana dengan baik bahkan para peserta terlihat proaktif dan kegiatan ini dapat berlanjut dengan pemberian materi lainnya terutama terkait tentang pemeriksaan IVA test, peserta penyuluhan juga mengharapkan akan adanya kegitan yang berkelanjutan sehingga semakin dapat meningkatkan pengetahuan masyarakat.

Berikut gambar pelaksanaan penyuluhan :
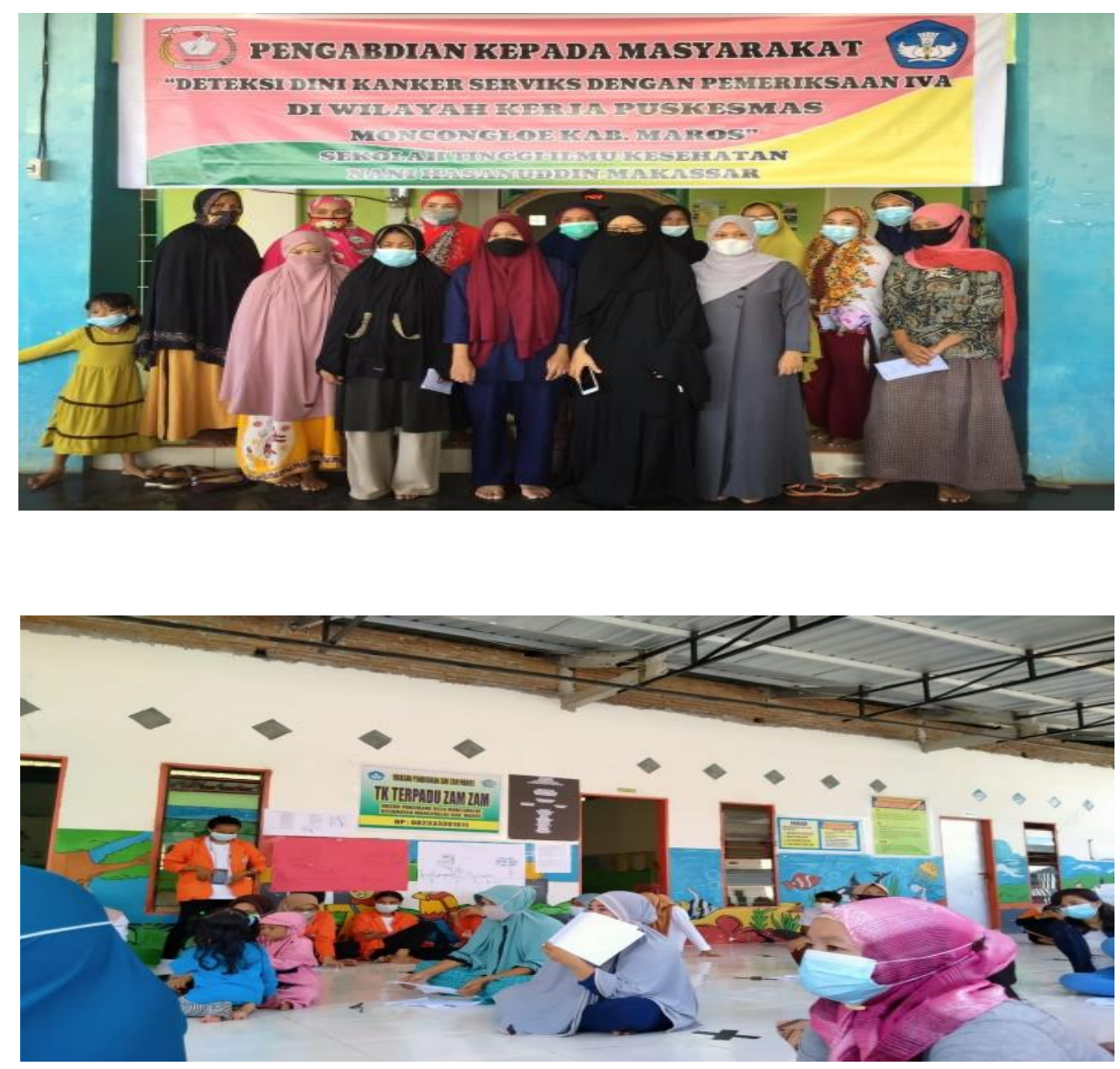

\section{KESIMPULAN}

Kegiatan pengabdian kepada masyarakat mengenai penyuluhan kanker serviks dengan pemerikaan IVA di wilayah kerja puskesmas Moncongloe telah terlaksana dengan baik. Para peserta yang hadir sangat bersemangat dan antusias dalam menyimak materi yang diberikan. Saran minimal setahun sekali ibu ibu dapat melakukan pemeriksaan IVA tes secara mandiri di Puskesmas Mongcongloe Dalam upaya peningkatan perilaku ibu dalam melakukan deteksi dini dan diperlukan dukungan yang dapat dilakukan oleh tenaga kesehatan, kader maupun oleh keluarga ibu. 


\section{DAFTAR PUSTAKA}

Arbyn, M., Gultekin, M., Morice, P., Nieminen, P., Cruickshank, M., Poortmans, P., ... Weiderpass, E. (2021). The European response to the $<\mathrm{scp}>\mathrm{WHO}</ \mathrm{scp}>$ call to eliminate cervical cancer as a public health problem. International Journal of Cancer, 148(2), 277-284. https: //doi.org/10.1002/ijc.33189

Chrystianty, N., Muarrofah, M., \& Puspitasari, M. T. (2021). Hubungan persepsi wanita pasangan usia subur tentang inspeksi visual asam asetat dengan motivasi pemeriksaan IVA. Jurnal Keperawatan,18(1),43-54. https://doi.org/10.35874/jkp.v18i1.804

Dyah Restuning Prihati, Maulidta Karunianingtyas Wirawati, E. S. (2021). Promkes Perilaku Cerdik Untuk Pencegahan Kanker Pada Kelompok Guru Bina Amal Semarang. 4, 96-101.

Eka Vicky Yulivantina, Bima Suryantara, Ade Elvina, Evellia Lofita Dini, Nyemas Sindya Utari, Harmiawati, \& Maria Magdalena Theofila Duka. (2020). Pemeriksaan IVA Test Pada Wanita Usia Subur Di Desa Kepuharjo, Cangkringan, Sleman. J.Abdimas: Community Health, 1(1), 6-10. https://doi.org/10.30590/jach.v1i1.229

Fariningsih, E., \& Pasaribu, I. I. I. P. C. D. (2020). Sosialisasi Deteksi Dini kanker serviks Dengan Pemeriksaan IVA(Inspeksi Visual Asam). Kesehatan.

Monica, L.P.,\&Ulfa,M.(2020). The Correlation of the Perception of Early Detection Cervical Cancer with Attitude to do Visual Inspection with Acetic Acid.Jurnal Ners Dan Kebidanan (Journal ofNers andMidwifery),7(1),044-049.

https: //doi.org/10.26699/jnk.v7i1.ART.p044-049

Nurbaity, Zulfendri, \& Rochadi, R. K. (2020). The Decision of Married Woman to Inspect IVA Test in Deli Serdang, Indonesia. Britain International of Exact Sciences (BloEx) Journal, 2(1), 35-44. https://doi.org/10.33258/bioex.v2i1.108

Tini Wartini, Sri Mulyani Nurhayati, Dwimeiyati, Nadya Suhannisa, W. P. (2020). peningkatan Pengetahuan dan keefektifan sosialisasi kanker serviks pada wanita masa repsoduksi di RW 02 Kelurahan Slipi Jakarta Barat. 2507(February), 1-9.

Vani Olin Arysha, Heru Santosa, \& Sri Rahayu Sanusi. (2020). The Effect of Extrinsic Motivation on Housewife Actions in IVA Test in the Working Area of Community Health Center at Bandar Kalipah. Britain International of Exact Sciences (BloEx) Journal, 2(1), 352-356. https://doi.org/10.33258/bioex.v2i1.164

Yuliani, I., Lusia, B.A., \& Widiati, E. N. (2020). Deteksi Dini Kanker Leher Rahim (Kanker Serviks) Dengan Metode IVA. Jurnal Pengabdian Dharma Bakti, 3(2), 8. https://doi.org/10.35842/jpdb.v3i2.117 